\title{
The effects of pressurization rate on breathing pattern, work of breathing, gas exchange and patient comfort in pressure support ventilation
}

\author{
D. Chiumello*, P. Pelosi\#, M. Croci*, L.M. Bigatello", L. Gattinoni*
}

\begin{abstract}
The effects of pressurization rate on breathing pattern, work of breathing, gas exchange and patient comfort in pressure support ventilation. D. Chiumello, P. Pelosi, M. Croci, L.M. Bigatello, L. Gattinoni. (C) ERS Journals Ltd 2001.

ABSTRACT: The aim of this study was to investigate the effects of different pressurization rates during pressure support ventilation on breathing pattern, work of breathing, gas exchange and patient comfort in patients with acute lung injury. The pressurization rate modifies the initial pressure ramp by changing the initial peak flow rate: the increase in pressurization rate is associated with a decrease in the time to reach the level of pressure support ventilation by increasing the peak flow rate.

Ten intubated patients (age $64 \pm 17 \mathrm{yrs}$, body mass index $24 \pm 17 \mathrm{Kg} \cdot \mathrm{m}^{-2}$, arterial oxygen tension/inspired oxygen fraction $214 \pm 59$ ) were studied in random order varying the pressurization rate at 5 and $15 \mathrm{cmH}_{2} \mathrm{O}$ of pressure support ventilation. Breathing comfort was evaluated by a visual analogue scale.

Increasing the pressurization rate caused an increase of peak flow rate from $473 \pm 141 \mathrm{~mL} \cdot \mathrm{s}^{-1}$ to $758 \pm 302 \mathrm{~mL} \cdot \mathrm{s}^{-1}$ at pressure support ventilation $5(\mathrm{p}<0.05)$ and from $481 \pm 126 \mathrm{~mL} \cdot \mathrm{s}^{-1}$ to $1,121 \pm 175 \mathrm{~mL} \cdot \mathrm{s}^{-1}$ at pressure support ventilation $15(\mathrm{p}<0.05)$. At the lowest pressurization rate the tidal volume was the lowest, the respiratory rate and the work of breathing were the highest $(\mathbf{p}<0.05)$ compared with other pressurization rates. Excluding the lowest pressurization rate, in all the other pressurization rates tested the breathing pattern and the work of breathing did not change. The lowest and the highest pressurization rates caused the worst patient comfort $(p<0.05)$. The gas exchange was stable throughout the study.

The presented results suggest: 1) the lowest pressurization rate caused the lowest tidal volume, highest respiratory rate and highest work of breathing; 2) at the other pressurization rates no differences in breathing pattern and work of breathing were observed; and 3) the patient's comfort was worse at the lowest and highest pressurization rates.
\end{abstract}

Eur Respir J 2001; 18: 107-114.

*Istituto di Anestesia e Rianimazione, Universita' di Milano, Milano; Ospedale Policlinico, IRCCS, Milano, Italia, \#Dipartimento di Scienze Cliniche e Biologiche, Universita' degli Studi dell'Insubria, Varese, Italia and "Istituto di Anestesia e Rianimazione, Università di Milano - Bicocca, Ospedale S. Gerardo, Monza, Italia.

Correspondence: L. Gattinoni, Istituto di Anestesia e Rianimazione, Ospedale Maggiore Policlinico-IRCCS, via Francesco Sforza 35, 20122 Milano, Italy. Fax: 390255033230

Keywords: Gas exchange patient comfort

peak inspiratory flow rate pressure support ventilation pressurization rate respiratory effort

Received: September 252000 Accepted after revision January 30 2001

Pressure support ventilation (PSV) is a useful means of increasing tidal volume $(V \mathrm{~T})$ of spontaneously breathing patients with respiratory failure, improving gas exchange while reducing respiratory muscle work; this is achieved by applying a preset positive pressure (i.e. pressure support) during each inspiratory effort [1].

PSV delivered by various mechanical ventilators is characterized by a nonadjustable velocity of pressurization (i.e. the time to set the pressure support level). This velocity of pressurization determines the initial pressure ramp profile and the initial peak inspiratory flow rate (PIF). Because a low PIF may result in excessive inspiratory effort [2], mechanical ventilators are designed to deliver the maximum PIF during the initial rise to pressure support level [3].

However, this fixed and fast rise of pressure into the respiratory system could deliver a PIF higher than some patients need, resulting in an unstable pressure delivery (overshoot) and/or premature end of inspiration [4]. An adjustable initial peak inspiratory flow could be an appropriate enhancement to improve the patient ventilator synchrony [5]. The newest mechanical ventilators allow regulations of the PIF during PSV, through the pressurization rate (PR) button, so that the PIF can be modified and tailored to the patients needs. In a bench study, a reduction of the work of breathing obtained by PR manipulations was described [6]. However, information about the effects of PR manipulations during clinical trials is controversial. MACINTYRE and Ho [7] found that an intermediate PIF improved patient-ventilator interaction [7], while other studies observed the lowest work of breathing at the highest PIF [8-10] and still others described an individual response to PIF manipulations, depending on the individual inspiratory drive [11]. However, these studies did not systematically evaluate the effects of changing the PIF on the subjective sensation of dyspnoea. Since dyspnoea often occurs during mechanical ventilation in settings in which the respiratory effort is increased, it was hypothesized that different pressurization rates can affect the patient comfort. 
The aim of this study was to evaluate the effect of varying the PR on the breathing pattern, work of breathing, gas exchange and patient comfort in patients with acute lung injury, at two different levels of pressure support ventilation.

\section{Methods}

\section{Subjects}

Ten intubated (four tracheostomized) patients with acute lung injury were enrolled in the study. All the patients were ventilated in PSV (table 1). To be included in the study, the patients had to be haemodynamically stable and without history and/or evidence of chronic obstructive pulmonary disease (COPD).

The protocol was approved by the institutional review board of the Universita' degli Studi di Milano, and informed consent was obtained from each patient or their next of kin.

\section{Protocol}

All patients were ventilated with a Bear 1000 (Allied Healthcare, Riverside, CA, USA) mechanical ventilator and studied in a semirecumbent position ( $\sim 30^{\circ}$ head-up). The PR during PSV could be adjusted through an arbitrary scale from -9 (lowest) to 9 (highest) in discrete steps of 1 unit with 0 as a default value [12]. The demand valve therefore modulates the PIF according to: the level of pressure support chosen, the PR, the patient's inspiratory impedance and inspiratory effort. The set level of pressure is reached after a variable interval of time, depending on the selected PR and each patient's mechanical characteristics. In general, the lowest PR means the longest time to reach a given level of PSV ( $t$ PSV) and minimum PIF, while the highest PR means the shortest $t$ PSV and maximum PIF. The inspiratory pressure stops when the inspiratory flow drops to $<30 \%$ of the PIF or when the patient begins active expiration. All patients were connected to the mechanical ventilator through a standard disposable respiratory circuit (1.8 $\mathrm{m}$ length; DAR, Mirandola, Italy) with a hot water humidifier (MR450, Fischer \& Paykel, Auckland, New Zealand) inserted into the inspiratory limb.

Two levels of PSV were applied in random order: 5 and $15 \mathrm{cmH}_{2} \mathrm{O}$ above peak end-expiratory pressure (PEEP). At each level of PSV, five levels of PR were applied in random order. The same levels of PR were studied at each level of PSV in all patients. Because at low PR the mechanical ventilator could fail to reach the preset pressure, the airway pressure tracing was checked in each patient to insure that the selected level of pressure support was effectively reached.

The trigger sensitivity was set at $0.5 \mathrm{cmH}_{2} \mathrm{O}$ and was unchanged throughout the study. The level of PEEP and inspiratory oxygen fraction $\left(F \mathrm{I}, \mathrm{O}_{2}\right)$ were maintained at the same level, chosen by the attending physician before the study. Each study step was maintained for $\geqslant 20 \mathrm{~min}$, and the measurements were taken over the last $5 \mathrm{~min}$ of each period.

\section{Measurements}

Flow was measured with a heated pneumotachograph (Fleish No 2; Fleish, Switzerland) inserted between the proximal tip of the endotracheal tube and the "Y"-piece of the breathing circuit. Airway opening pressure was measured proximal to the pneumotachograph by a pressure transducer (Validyne Corp., Northridge, CA, USA). Oesophageal pressure $\left(P_{\mathrm{oes}}\right)$ was recorded using a thin-walled latex balloon $(8 \mathrm{~cm}$ long) sealed over one end of a polyethylene catheter and connected to a pressure transducer (Bentley Trantec; Bentley Laboratories, Irvine, CA, USA). During measurements, the oesophageal balloon was inflated with $0.5-1.0 \mathrm{~mL}$ of air. The position of the oesophageal balloon and validity of its signal were assessed by the occlusion test [13] and by chest radiograph. It was then fixed in that position. In six patients a similar catheter was advanced into the stomach to measure gastric pressure. Its position was confirmed by pressure tracings. Both flow and pressure signals were recorded on a polygraph (Brush 2400 S, Gould, Cleveland, OH, USA), processed via an analogue-to-digital converter (100 Hz per channel)

Table 1. - Patients' characteristics

\begin{tabular}{lcccccccl}
\hline Patient no. & Sex & Age yrs & $\mathrm{BMI} \mathrm{kg} \cdot \mathrm{m}^{-2}$ & $\mathrm{PSV} \mathrm{cmH}_{2} \mathrm{O}$ & $\mathrm{PEEP} \mathrm{cmH}_{2} \mathrm{O}$ & $V^{\prime} \mathrm{E} \mathrm{L} \cdot \mathrm{min}^{-1}$ & $\mathrm{~Pa}_{2} \mathrm{O}_{2} / \mathrm{FiO}_{2}$ & Diagnosis \\
\hline 1 & $\mathrm{M}$ & 67 & 22.7 & 10 & 2 & 11.2 & 298 & Peritonitis \\
2 & $\mathrm{M}$ & 82 & 31.1 & 8 & 4 & 10.6 & 220 & Hypovolemic shock \\
3 & $\mathrm{~F}$ & 56 & 23.4 & 10 & 8 & 9.8 & 290 & Pneumonia \\
4 & $\mathrm{~F}$ & 76 & 29.2 & 8 & 4 & 14.7 & 140 & Pneumonia \\
5 & $\mathrm{~F}$ & 85 & 20.0 & 8 & 6 & 10.7 & 146 & Peritonitis \\
6 & $\mathrm{~F}$ & 24 & 17.5 & 7 & 4 & 10.2 & 282 & Stroke \\
7 & $\mathrm{~F}$ & 59 & 29.3 & 10 & 6 & 13.8 & 178 & Septic shock \\
8 & $\mathrm{M}$ & 65 & 27.6 & 8 & 4 & 15.4 & 223 & Peritonitis \\
9 & $\mathrm{M}$ & 69 & 21.6 & 6 & 4 & 8.4 & 200 & Pneumonia \\
10 & $\mathrm{M}$ & 64 & 22.1 & 8 & 4 & 10.1 & 169 & Pneumonia \\
Mean \pm SD & $5 \mathrm{M}: 5 \mathrm{~F}$ & $64.7 \pm 17$ & $24.5 \pm 17$ & $8.3 \pm 1.3$ & $4.6 \pm 1.6$ & $11.4 \pm 1.6$ & $214.6 \pm 58.8$ & \\
\hline
\end{tabular}

M: male; F: female; BMI: body mass index; PSV: pressure support ventilation; PEEP: peak end-expiratory pressure; $V^{\prime} E$ : minute ventilation; $\mathrm{Pa}, \mathrm{O}_{2} / \mathrm{FiO}_{2}$ : arterial oxygen tension/inspired oxygen fraction. 
and stored on a personal computer for subsequent analysis and computations.

All patients had indwelling arterial cannula. Blood pressure and heart rate were monitored by a disposable pressure transducer (Transpec IV L974; Abbott Ireland, Sligo, Republic of Ireland). Arterial blood samples were taken and blood gases were assessed by means of gas-analyser (IL-1312 Blood Gas Manager and IL-282 CO-Oximetry, Instrumentation Laboratory, Milano, Italy).

\section{Pattern of breathing and respiratory effort}

In the initial $2 \mathrm{~min}$ of each measurement period consecutive undisturbed breaths were recorded to measure $V \mathrm{~T}$, respiratory rate $(\mathrm{RR})$, minute ventilation $\left(V^{\prime} \mathrm{E}\right)$, inspiratory time $(t \mathrm{I})$, duty cycle $(t \mathrm{I} /$ total time: $t \mathrm{I} /$ t tot $), t \mathrm{PSV}, \mathrm{PIF}$, the inspiratory mechanical work of breathing (WOB) expressed either per min $\left(\mathrm{WOB} \cdot \mathrm{min}^{-1}\right)$ or per $\mathrm{L}$ of ventilation $\left(\mathrm{WOB} \cdot \mathrm{L}^{-1}\right)$, the pressure time product (PTP), and the dynamic intrinsic PEEP (PEEPi). VT was obtained by mathematical integration of flow signal, $V^{\prime} \mathrm{E}$ was calculated as $V \mathrm{~T} \times \mathrm{RR}$. The WOB was computed from a modified Campbell's diagram as previously reported [14]; the elastic recoil pressure of the chest wall was taken at the point of sharp inspiratory inflection on $P_{\text {oes }}$ tracings, (i.e. at the onset of inspiratory effort) [14]. The elastic and resistive work of the chest wall was not measured because this measurement requires deep sedation of the patients. The PTP was calculated as the integral of the Poes tracing versus time from the beginning of the inspiration deflection to the end of the inspiratory flow, assuming the chest wall elastance was linear within the range of $V \mathrm{~T}$, and multiplied by respiratory rate [15]. To assess the possible influence of expiratory activity which may cause errors in the computation of PEEPi and WOB, gastric pressure was measured in six patients. The absence of expiratory muscle activity was checked by inspecting the gastric pressure tracings [16]. In the remaining four patients such recordings were not obtained but expiratory muscle activity could be excluded by clinical inspection as suggested by previous authors [14]. PEEPi was considered equal to the difference between the $P_{\text {oes }}$ value at the onset of negative deflection and its value corresponding to the first point at zero flow [14].

In the last 3 min of each study step, a series of three end-expiratory occlusion manoeuvres, repeated $\sim 15 \mathrm{~s}$ apart, were performed to measure ventilatory drive $(P 0.1) . P 0.1$ was taken as the value of airway pressure drop at the beginning of inspiratory effort during the occlusion manoeuvre, over the initial $0.1 \mathrm{~s}$ after the point of zero flow [17].

\section{Patient comfort}

The patient comfort of breathing was evaluated by a physician not involved in the study, on the basis of the visual analogue scale "Borg Perceived Dyspnoea Scale" [18]. Subjects were asked to place a vertical mark on a printed $10-\mathrm{cm}$ horizontal scale in response to the question: "How short of breath are you right now?" The line had descriptors below the extreme ends. On the left was the word "none" indicating no shortness of breath, and on the right was the opposite response "extremely severe". For each condition tested, patients placed a vertical mark on the line that best represented the intensity of their dyspnoea. Intensity was measured as the distance in $\mathrm{cm}$ from the left side of the horizontal line (corresponding to no dyspnoea) to the mark placed by the patient. A fresh scale was presented each time the measurements of patient comfort were assessed [19]. The patients were carefully instructed on the appropriate use of the scale before the beginning of protocol. The sensitivity and the reproducibility of the Borg scale has been validated with other measures of dyspnoea [20-22].

\section{Statistics}

All results are expressed as mean \pm sD. Comparison between means for each sequence and each variable measured was performed by two way analysis of variance with internal comparison between sequence by a postanalysis Bonferroni t-test when appropriate, accepting $\mathrm{p}<0.05$ as statistically significant. Linear regressions were performed when appropriate.

\section{Results}

\section{Effects of pressure support ventilation changes}

As expected, the $V \mathrm{~T}$ and PIF were higher at PSV 15 compared to PSV $5(\mathrm{p}<0.05)$ (tables 2 and 3$)$. The WOB (WOB $\cdot \mathrm{min}^{-1}$ and $\mathrm{WOB} \cdot \mathrm{L}^{-1}$ ) and PTP were lower with PSV 15 versus PSV $5(\mathrm{p}<0.05)$. There were no differences in $P 0.1$ and dyspnoea levels between the two levels of PSV.

\section{Effects of pressurization rate changes}

A representative experimental recording of one patient during PSV at different PR is shown in figure 1. Due to the experimental design, the increase of PR led to a significant increase of PIF from $473 \pm 141 \mathrm{~mL} \cdot \mathrm{s}^{-1}$ to $758 \pm 302 \mathrm{~mL} \cdot \mathrm{s}^{-1}$ at PSV $5(\mathrm{p}<0.05)$ and from $481 \pm 126 \mathrm{~mL} \cdot \mathrm{s}^{-1}$ to $1,121 \pm 175 \mathrm{~mL} \cdot \mathrm{s}^{-1}$ at PSV $15(\mathrm{p}<0.05)$, and a decrease of $t$ PSV from $1.0 \pm 0.4 \mathrm{~s}$ to $0.1 \pm 0.1 \mathrm{~s}$ at PSV $5(\mathrm{p}<0.05)$ and from $1.0 \pm 0.3 \mathrm{~s}$ to $0.2 \pm 0.2 \mathrm{~s}$ at PSV $15(\mathrm{p}<0.05)$ (tables 2 and 3$)$.

At the lowest PR the $V \mathrm{~T}$ was lower and the RR, the indexes of patient effort and the dyspnoea level were higher compared with other PR $(\mathrm{p}<0.05)$ (tables 2 and 3 and fig. 2). However, excluding the lowest PR, in the other PR tested, the $V \mathrm{~T}$, the RR, the work of breathing and $P 0.1$ did not change significantly. The response of patient comfort to the increase in PR was U shaped (fig. 3), with the lowest and the highest PR corresponding to the highest dyspnoea levels at both PSV $(p<0.05)$. As shown in figure 4, there was a marked interindividual variability of the values of PR at which the best patient comfort was found. The 
Table 2. - Effects of different pressurization rates (PR) at $5 \mathrm{cmH}_{2} \mathrm{O}$ of pressure support ventilation (PSV)

\begin{tabular}{|c|c|c|c|c|c|}
\hline \multirow[t]{2}{*}{ Characteristic } & \multicolumn{5}{|c|}{ PR } \\
\hline & Lowest & Low & Baseline & High & Highest \\
\hline RR bpm & $32 \pm 13^{\#}$ & $30 \pm 12$ & $30 \pm 10$ & $29 \pm 9$ & $32 \pm 10$ \\
\hline$V \mathrm{~T} \mathrm{~mL}$ & $272 \pm 91^{\uparrow, \# \#}$ & $342 \pm 88^{\# \#}$ & $334 \pm 104^{\# \#}$ & $376 \pm 99^{\oplus, \# \#}$ & $334 \pm 74^{\# \#}$ \\
\hline$V^{\prime} \mathrm{E} L \cdot \mathrm{min}^{-1}$ & $7.9 \pm 2.0^{\circ}$ & $9.7 \pm 2.8$ & $9.5 \pm 2.8$ & $10.5 \pm 2.4$ & $10.4 \pm 2.7$ \\
\hline$t \mathrm{I} \mathrm{S}$ & $1.0 \pm 0.4$ & $0.9 \pm 0.3$ & $0.8 \pm 0.3$ & $0.9 \pm 0.3$ & $0.9 \pm 0.2$ \\
\hline$t \mathrm{t} /$ tot & $0.47 \pm 0.08$ & $0.42 \pm 0.05$ & $0.40 \pm 0.05$ & $0.40 \pm 0.05$ & $0.42 \pm 0.05$ \\
\hline$t$ PSV s & $1.0 \pm 0.4$ & $0.9 \pm 0.3^{\Phi}$ & $0.4 \pm 0.2$ & $0.2 \pm 0.09$ & $0.1 \pm 0.1^{+}$ \\
\hline PIF $\mathrm{mL} \cdot \mathrm{s}^{-1}$ & $473 \pm 141^{\text {๙,\#\# }}$ & $602 \pm 194^{\# \#}$ & $660 \pm 168^{\# \#}$ & $685 \pm 204^{\# \#}$ & $758 \pm 302^{\#, \# \#}$ \\
\hline Dyspnoea cm & $2.7 \pm 1.1^{\S}(1-4)$ & $1.6 \pm 1(1-3)$ & $1.2 \pm 0.4(1-2)$ & $1.5 \pm 1(0-3)$ & $2.4 \pm 1.5^{f}(0.5-5)$ \\
\hline $\begin{array}{l}\mathrm{PTP} \mathrm{cmH}_{2} \mathrm{O} \times \\
\mathrm{s} / \mathrm{min}\end{array}$ & $\begin{array}{l}340 \pm 150^{\bullet, \# \#} \\
(139-522)\end{array}$ & $\begin{array}{l}220 \pm 122^{\# \#} \\
(51-379)\end{array}$ & $\begin{array}{l}141 \pm 76^{\# \#} \\
(45-221)\end{array}$ & $\begin{array}{c}159 \pm 87^{\# \#} \\
(25-291)\end{array}$ & $\begin{array}{c}180 \pm 84^{\# \#} \\
(46-314)\end{array}$ \\
\hline $\mathrm{WOB} \cdot \mathrm{min}^{-1}$ & 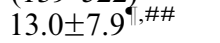 & $11.3 \pm 7.8^{\# \#}$ & $7.6 \pm 5.5^{\# \#}$ & $8.9 \pm 6.2^{\# \#}$ & $10.4 \pm 7.7^{\# \#}$ \\
\hline $\mathrm{J} \cdot \mathrm{min}^{-1}$ & $(4.4-24)$ & $(2-17.4)$ & $(0.9-15.8)$ & $(1-20.4)$ & $(1.6-28.7)$ \\
\hline $\mathrm{WOB} \cdot \mathrm{L}^{-1} \mathrm{~J} \cdot \mathrm{L}^{-1}$ & $1.53 \pm 0.6^{\uparrow, \# \#}$ & $1.04 \pm 0.5^{\# \#}$ & $0.71 \pm 0.4^{\# \#}$ & $0.77 \pm 0.4^{\# \#}$ & $0.93 \pm 0.5^{\# \#}$ \\
\hline & $(0.8-2.6)$ & $(0.4-1.7)$ & $(0.3-1.3)$ & $(0.4-1.4)$ & $(0.2-2.0)$ \\
\hline $\mathrm{PEEP}_{\mathrm{i}} \mathrm{cmH}_{2} \mathrm{O}$ & $1.4 \pm 1.1$ & $1.6 \pm 1.4$ & $1.3 \pm 0.8$ & $1.4 \pm 0.9$ & $1.6 \pm 0.9$ \\
\hline$P 0.1 \mathrm{cmH}_{2} \mathrm{O}$ & $3.7 \pm 2.6^{\circ}$ & $2.5 \pm 1.6$ & $2.1 \pm 1.3$ & $1.8 \pm 1.1$ & $2.4 \pm 1.6$ \\
\hline
\end{tabular}

Data are presented as mean \pm SD (range). RR: respiratory rate; $\mathrm{bpm}$ : breaths $\cdot \mathrm{min}^{-1} ; V_{\mathrm{T}}$ : tidal volume; $V^{\prime} \mathrm{E}$ : minute ventilation; $t \mathrm{I}$ : inspiratory time; $t \mathrm{I} /$ tot: duty cycle; $t$ PSV: time to reach pressure support level; PIF: peak inspiratory flow; dyspnoea: Borg's dyspnoea scale; PTP: pressure time product; WOB $\cdot \mathrm{min}^{-1}$ : work of breathing per minute; WOB $\cdot \mathrm{L}^{-1}$ : work of breathing per L of ventilation; PEEP $_{\mathrm{i}}$ : dynamic intrinsic positive end-expiratory pressure; $P 0.1$ : mouth occluded airway pressure at $0.1 \mathrm{~s}$. All p-value are $<0.05$ for the following: ${ }^{\#}$ : versus low $\mathrm{PR} ;{ }^{\natural}$ : versus low, baseline, high, highest $\mathrm{PR} ;{ }^{+}$: versus baseline; ${ }^{\S}$ : versus low, baseline, high PR; ${ }^{f}$ : versus low, baseline PR; ${ }^{\# \#}$ : versus PSV 15.

patients presented different responses, because at PSV 5 the best comfort was found in six patients at baseline PR, while at PSV 15 the best comfort was present at low PR in four patients and at baseline PR in five (fig. 4). There were no correlations between the dyspnoea score and the respiratory effort (i.e. PTP and $\mathrm{WOB}$ ) and $P 0.1$.

The gas exchange remained stable between different levels of PSV and PR, the mean arterial oxygen tension $\left(\mathrm{Pa}, \mathrm{O}_{2}\right)$ was $85 \pm 20 \mathrm{mmHg}$ and the mean arterial carbon dioxide tension $\left(\mathrm{Pa}, \mathrm{CO}_{2}\right)$ was $33 \pm 3 \mathrm{mmHg}$. There were no significant changes in blood pressure and heart rate throughout the study.

\section{Discussion}

The presented study shows that in patients with acute lung injury, different PR during PSV may

Table 3. - Effects of different pressurization rates (PR) at $15 \mathrm{cmH}_{2} \mathrm{O}$ of pressure support ventilation (PSV)

\begin{tabular}{|c|c|c|c|c|c|}
\hline \multirow[t]{2}{*}{ Characteristic } & \multicolumn{5}{|c|}{ PR } \\
\hline & Lowest & Low & Baseline & High & Highest \\
\hline RR bpm & $31 \pm 9^{\#}$ & $23 \pm 7$ & $27 \pm 7$ & $27 \pm 7$ & $31 \pm 9$ \\
\hline$V \mathrm{~T} \mathrm{~mL}$ & $278 \pm 89^{\bullet, \# \#}$ & $433 \pm 106^{\# \#}$ & $430 \pm 92^{\# \#}$ & $433 \pm 104^{\# \#}$ & $367 \pm 82^{\# \#}$ \\
\hline$V^{\prime} \mathrm{E} L \cdot \min ^{-1}$ & $8.3 \pm 2.4$ & $9.9 \pm 3.2$ & $11.4 \pm 3.3$ & $11.2 \pm 2.4$ & $10.9 \pm 2.4$ \\
\hline$t \mathrm{I} \mathrm{s}$ & $1.1 \pm 0.3^{*}$ & $1.1 \pm 0.4$ & $0.9 \pm 0.2$ & $0.8 \pm 0.2$ & $0.8 \pm 0.2$ \\
\hline$t \mathrm{I} /$ t tot & $0.53 \pm 0.08$ & $0.45 \pm 0.08$ & $0.38 \pm 0.04$ & $0.35 \pm 0.03$ & $0.38 \pm 0.06$ \\
\hline$t \mathrm{PSV} \mathrm{s}$ & $1.0 \pm 0.3^{\bullet}$ & $0.7 \pm 0.2^{\bullet}$ & $0.4 \pm 0.2$ & $0.2 \pm 0.13$ & $0.2 \pm 0.2^{+}$ \\
\hline $\mathrm{PIF} \mathrm{mL} \cdot \mathrm{s}^{-1}$ & $481 \pm 126^{\oplus, \# \#}$ & $673 \pm 191^{\top, \# \#}$ & $860 \pm 167^{\# \#}$ & $943 \pm 154^{\# \#}$ & $1121 \pm 175^{\#, \# \# ~}$ \\
\hline Dyspnoea cm & $3.7 \pm 1.8^{\S}(2-7)$ & $1.5 \pm 1.5(0-5)$ & $1.4 \pm 1.4(0-5)$ & $2.6 \pm 1.5(0-5)$ & $3.1 \pm 1.3^{f}(1-5)$ \\
\hline$\underset{\mathrm{s} / \mathrm{min}}{\mathrm{PTm}}$ & $\begin{array}{l}276 \pm 127^{\circ /, \# \#} \\
(165-477)\end{array}$ & $\begin{array}{l}88 \pm 92^{\# \#} \\
(21-268)\end{array}$ & $\begin{array}{c}67 \pm 67^{\# \#} \\
(2-151)\end{array}$ & $\begin{array}{c}60 \pm 62^{\# \#} \\
(4-191)\end{array}$ & $\begin{array}{l}101 \pm 100^{\# \#} \\
(7-325)\end{array}$ \\
\hline $\mathrm{WOB} \cdot \mathrm{min}^{-1}$ & $10.6 \pm 7.4^{\boldsymbol{⿰}}$ & $4.9 \pm 6.5^{\text {\#\# }}$ & $4.6 \pm 5.3^{\# \#}$ & $4.0 \pm 5.1^{\# \#}$ & $5.6 \pm 5.6^{\# \#}$ \\
\hline $\mathrm{J} \cdot \mathrm{min}^{-1}$ & $(2.9-23.4)$ & $(0.2-17.1)$ & $(0.2-14.9)$ & $(0.3-14.6)$ & $(0.2-12.8)$ \\
\hline $\mathrm{WOB} \cdot \mathrm{L}^{-1} \mathrm{~J} \cdot \mathrm{L}^{-1}$ & $1.2 \pm 0.6$ & $0.4 \pm 0.5^{\# \#}$ & $0.3 \pm 0.3^{\# \#}$ & $0.3 \pm 0.3^{\# \#}$ & $0.5 \pm 0.5^{\# \#}$ \\
\hline & $(0.5-2.1)$ & $(0.04-1.3)$ & $(0.01-1)$ & $(0.04-1.2)$ & $(0.08-1.5)$ \\
\hline PEEPi $\mathrm{cmH}_{2} \mathrm{O}$ & $1.6 \pm 1.1$ & $1.5 \pm 0.9$ & $1.0 \pm 1.2$ & $0.9 \pm 0.6$ & $1.7 \pm 1.6$ \\
\hline$P 0.1 \mathrm{cmH}_{2} \mathrm{O}$ & $3.5 \pm 2$ & $1.7 \pm 1.4$ & $1.5 \pm 1.2$ & $1.9 \pm 1.4$ & $2.0 \pm 1.3$ \\
\hline
\end{tabular}

Data are presented as mean $\pm \mathrm{SD}$ (range). RR: respiratory rate; bpm: breaths $\cdot \mathrm{min}^{-1} ; V_{\mathrm{T}}$ : tidal volume; $V^{\prime} \mathrm{E}$ : minute ventilation; $t \mathrm{I}$ : inspiratory time; $t \mathrm{I} / \mathrm{ttot}$ duty cycle; $t \mathrm{PSV}$ : time to reach pressure support level; PIF: peak inspiratory flow; dyspnoea: Borg's dyspnoea scale; PTP: pressure time product; WOB $\cdot \mathrm{min}^{-1}$ : work of breathing per minute; WOB $\cdot \mathrm{L}^{-1}$ : work of breathing per $\mathrm{L}$ of ventilation; PEEPi: dynamic intrinsic positive end-expiratory pressure; P0.1: mouth occluded airway pressure at $0.1 \mathrm{~s}$. All p-values are $<0.05$ for the following: ${ }^{*}$ : versus low PR; ${ }^{\uparrow}$ : versus low, baseline, high, highest PR; *: versus high, highest PR; ${ }^{+}$: versus baseline; $\$$ : versus low, baseline, high PR; ${ }^{f}$ : versus low, baseline PR; \#\#: versus PSV 5. 

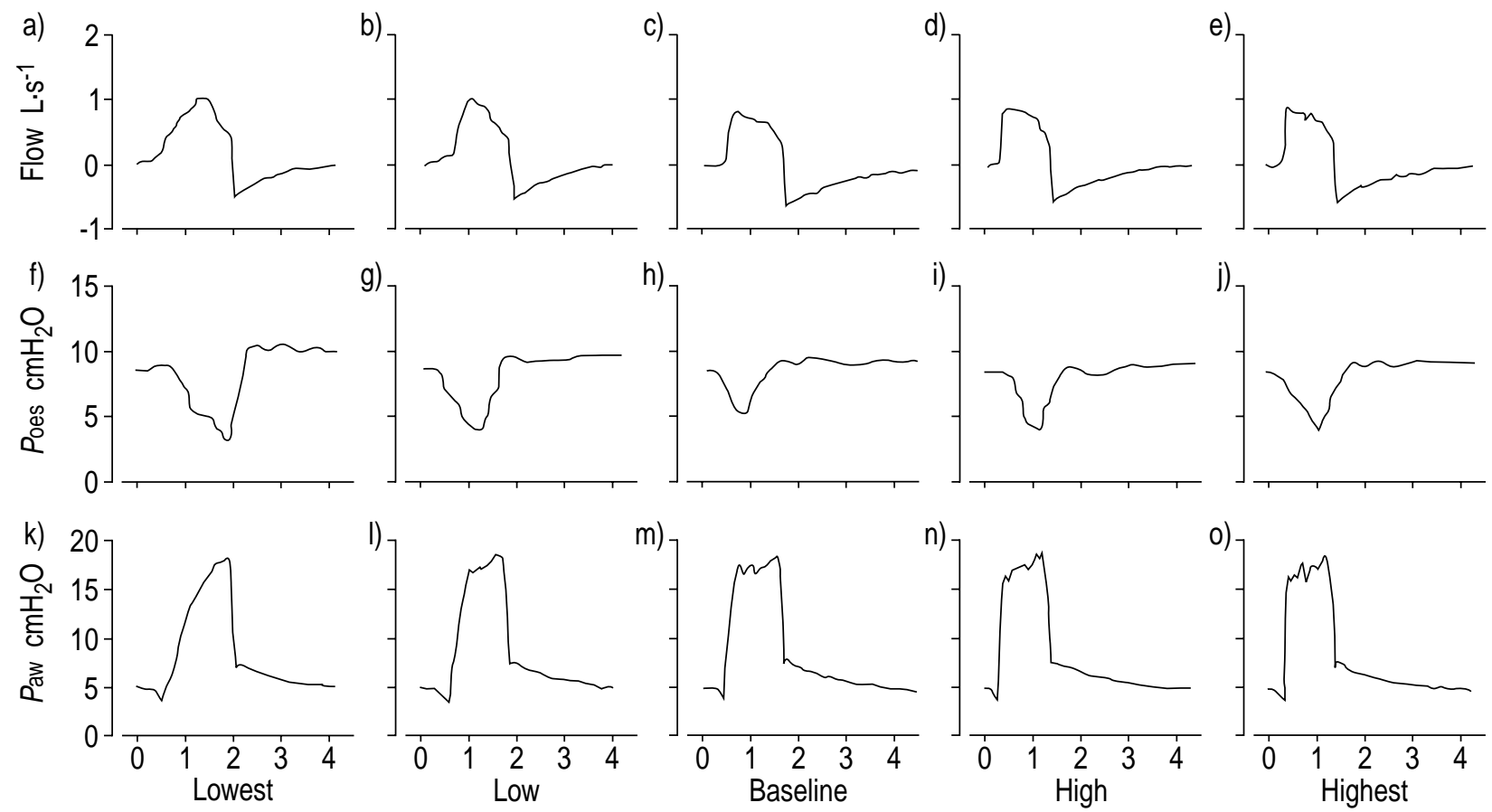

Time $s$

Fig. 1. - An example of a-e) airflow, $\mathrm{f}-\mathrm{j})$ oesophageal pressure $\left(P_{\mathrm{oes}}\right)$ and $\left.\mathrm{k}-\mathrm{o}\right)$ airway pressure $\left(P_{\mathrm{aw}}\right)$ tracing at five different pressurization rates.
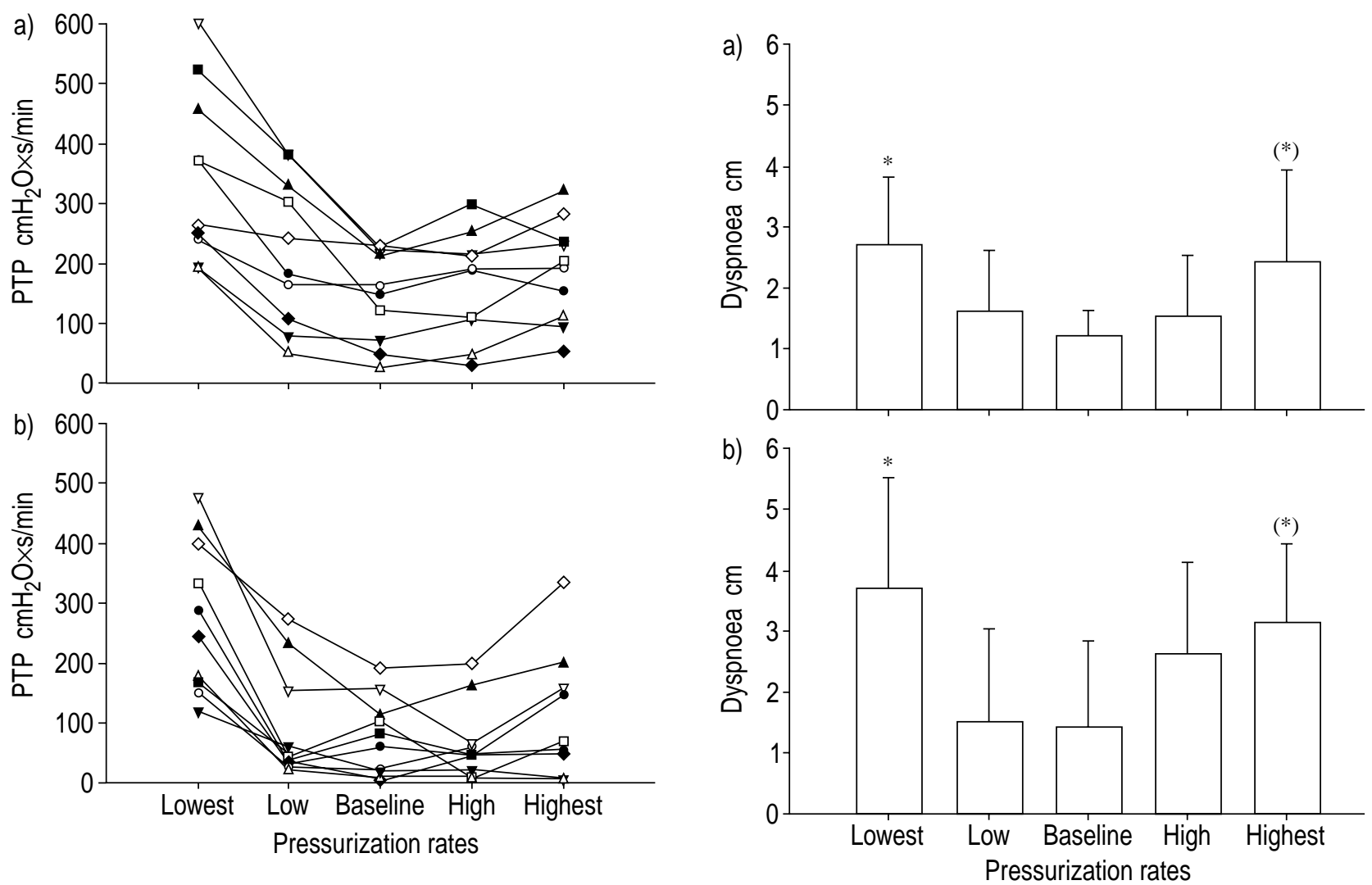

Fig. 2. - Effects of pressurization rates on the pressure time product (PTP) at a) 5 and b) $15 \mathrm{cmH}_{2} \mathrm{O}$ of pressure support ventilation. Data are shown for each of the 10 patients represented by different symbols.

Fig. 3. - The dyspnoea levels at each pressurization rate (PR) at a) 5 and b) $15 \mathrm{cmH}_{2} \mathrm{O}$ of pressure support ventilation. *: $\mathrm{p}<0.05$ versus low, baseline PR (baseline PR). 

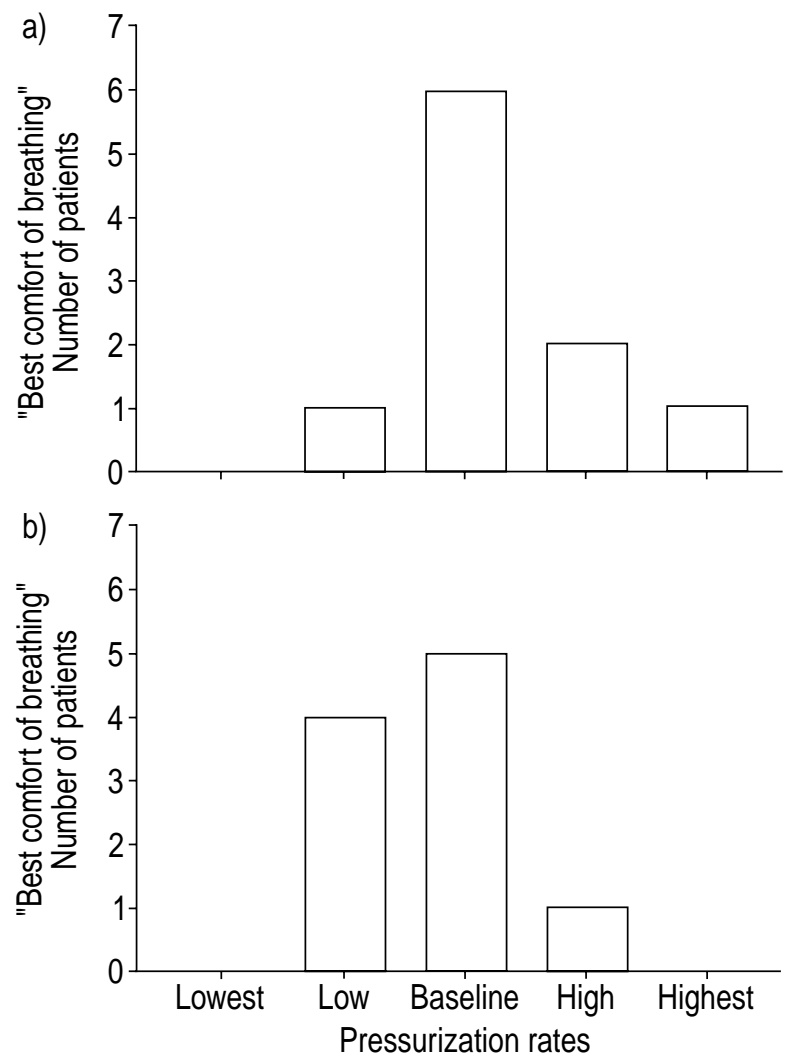

Fig. 4.-The distribution of the best comfort of breathing in each patient with respect to the pressurization rate at a) 5 and b) $15 \mathrm{cmH}_{2} \mathrm{O}$ of pressure support ventilation.

significantly influence ventilatory pattern, work of breathing and patient comfort.

During PSV, once triggered, the ventilator usually provides the maximum possible PIF to quickly reach the set level of pressure support [3]. Normally the PIF is not set by the clinician and may be variable among manufacturers [3]. A fixed setting may be inappropriate, as many studies have demonstrated that variations in the PIF caused important modifications in the breathing pattern [7-11]. It was reasoned that modulating the PIF throughout changes in the PR may affect the patient's respiratory effort and subjective sensation of breathing comfort.

In four out of 10 patients the expiratory activity was not directly measured by recording the gastric pressure tracings. The presence of expiratory activity in these four patients could lead to an overestimation of PEEPi and inspiratory WOB and an underestimation of the total WOB. However, in the six patients in whom the gastric pressure was actually measured, no expiratory activity was detected. Also, in the four patients in whom the gastric pressure was not measured, any expiratory activity could reasonably be excluded by visual inspection. Moreover, the values of PEEPi in the whole population were very low and did not change through the protocol. Thus, even if all PEEPi was due to expiratory activity, this should have been low and not affected by PR. With these limitations in mind, the highest values of WOB and PTP and the greatest dyspnoea levels were found at the lowest PR levels. This may be due to an initial mismatch between the gas flow rate delivered by the ventilator and the patient's spontaneous demand for airflow. Similar results were found by others both during assistcontrol ventilation [2] and pressure-support ventilation [8-10] or continuous positive airway pressure [23].

Increasing levels of PR were always associated with a lower WOB. However, at the highest PR a trend towards an increase of the WOB was observed (tables 2 and 3 ).

The results in the literature relative to the relationship between the WOB and PR are not straightforward. BONMARCHAND et al. [9], using a different mechanical ventilator from the one used in the presented study, found, on average, a progressive reduction in WOB associated with progressive increase in PR. However, they also found a great variability in individual response. From their work, as well as the present results, it appears that the highest PR is not necessarily associated with the lowest WOB, suggesting that individual titration of PR may be useful. It is possible that the lowest achievable level of WOB depends on the individual demand and its match with the delivered flow. During PSV, an excess PIF may help to reduce the WOB during the initial phase of inspiration, but, due to the fixed cycling criterion of inspiration of the ventilator, an excessive PIF may decrease the actual inspiratory time to a value lower than the neural inspiratory time [3, 24]. This reduces the $V \mathrm{~T}$ and may create dysynchrony [11].

The changes of $P 0.1$ associated with the PR closely followed the changes of the WOB. These findings are in apparent contradiction with the work of ALBERTI et al. [17] who found a significant decrease of $P 0.1$ between 20 and $15 \mathrm{cmH}_{2} \mathrm{O}$ of PSV. However, AlberTI et al. [17] did not report any significant change in $P_{0.1}$ between 15 and $10 \mathrm{cmH}_{2} \mathrm{O}$ of PSV (i.e. a range of PSV similar to the presented study) [17]. Several factors may increase $P_{0.1}$, mechanical or chemical. In the present study, no major alteration in lung mechanics or gas exchange was found. However, regardless of the cause of an increased of $P_{0.1}$ it reflected the mismatch between patient demand and the airflow delivered by the machine.

The most surprising results of this study are about the patient comfort. The comfort of breathing during mechanical ventilation is difficult to quantify. AITKEN [25] recommended its measurement by using the Borg dyspnoea scale as a means of accurately assessing the subjective experiences. This dyspnoea scale showed a high reproducibility [20]. In alert, cooperative patients, the dyspnoea scale sensitively measures the intensity change in comfort in response to various stimulus during mechanical ventilation [19]. A Borg scale was used because it is simple to use and represents the entire response range, from full comfort to severe dyspnoea $[20,21]$. The present study reveals that the relationship between the PR and patient comfort could be described as a parabola (fig. 3). Patient comfort was worst at the lowest PR, and the patients described their discomfort with phrases such as: "I need more air" and "I need more oxygen". This was paralleled by an increase in WOB and PTP. Conversely, the highest PR was not the optimal 
setting because patient comfort was worse while WOB and PTP were not different compared to baseline. The patients described this sensation as "airway discomfort" but not breathlessness [26]. Therefore, there seemed to be a dissociation between the respiratory effort and dyspnoea sensation. This observation is in line with those of Grassino et al. [27] who found that exercise could induce marked dyspnoea in patients with COPD without any signs of diaphragmatic fatigue. Moreover, MANNING et al. [26] found an increased sensation of dyspnoea in mechanically ventilated patients when the PIF was increased. The present findings suggest that an increase in respiratory effort does not necessarily contribute to dyspnoea [28]. Dyspnoea has been related to an increased breathing effort in normal subjects [29] and in patients with COPD [30]. In the presented patients the dyspnoea levels were relatively low, although they fulfilled the acute lung injury (ALI)/acute respiratory distress syndrome (ARDS) criteria and were recovering from ALI/ARDS so they may constitute an altogether different population than the ones in which the dyspnoea scale has been validated. There is no clear explanation for this finding, but possible reasons include different type of lung injury, the prolonged effects of mechanical ventilation and a possible residual pharmacological sedation or a perturbation of physiological mechanism leading to dyspnoea.

In conclusion, the presented data confirm that is possible to minimize the work of breathing in a given patient by setting the proper pressurization rate according to the dyspnoea scale. A similar decrease in work of breathing may be obtained by increasing the level of pressure support ventilation, as previously described [31]. This, however, would increase the mean airway pressure and the tidal volume with possible induction of intrinsic peak end-expiratory pressure [32]. Setting the pressurization rate according to the patient comfort may decrease work of breathing, maintaining a more physiological breathing pattern than would be achieved by increasing the level of pressure support ventilation.

Acknowledgements. The authors would like to thank L. Brochard for his helpful review of the manuscript.

\section{References}

1. MacIntyre NR. Clinically available new strategies for mechanical ventilation support. Chest 1993; 104: 560 565.

2. Marini JJ, Capps JS, Culver BH. The inspiratory work of breathing during assisted mechanical ventilation. Chest 1985; 87: 612-618.

3. MacIntyre NR, Nishimura M, Usada Y, Tokioka H, Takezawa J, Shimada Y. The Nagoya conference on system design and patient-ventilator interactions during pressure support ventilation. Chest 1990; 97: 1463-1466.

4. Coehn IL, Bilen Z, Krishwamurthy S. The effects on ventilator working pressure curing pressure support ventilation. Chest 1993; 103: 588-592.

5. Brochard L. Pressure support ventilation: still a simple mode? Intensive Care Med 1996; 22: 1137-1138.

6. Croci M, Pelosi P, Chiumello D, Gattinoni L. Regulation of pressurization rate reduces inspiratory effort during pressure support ventilation: a bench study. Respiratory Care 1996; 41: 880-884.

7. MacIntyre NR, Ho LI. Effects of initial flow rate and breath termination criteria on pressure support ventilation. Chest 1991; 99: 134-138.

8. Bonmarchand G, Chevron V, Chopin C, et al. Increased initial flow rate reduces inspiratory work of breathing during pressure support ventilation in patients with exacerbation of chronic obstructive pulmonary disease. Intensive Care Med 1996; 22: 1147-1154.

9. Bonmarchand G, Chevron V, Menard JF, et al. Effect of pressure ramp slope values on the work of breathing during pressure support ventilation in restrictive patients. Crit Care Med 1999; 27: 715-722.

10. Mancebo J, Amaro P, Mollo JL, Lorino HF, Lemaire $\mathrm{F}$, Brochard L. Comparison of the effects of pressure support ventilation delivered by three different ventilators during weaning from mechanical ventilation. Intensive Care Med 1995; 21: 913-919.

11. Branson RD, Campbell RS, Davis K, Johanngman JA, Johnson DJ, Hurst JM. Altering flow rate during maximum pressure support ventilation (PSV max): effects on cardiorespiratory function. Respir Care 1990; 35: 1056-1064.

12. Bear 1000 mechanical ventilator. Instructions manual, Allied Healthcare Inc., Riverside, CA, USA.

13. Baydur A, Behrakis PK, Zin WA, Jaeger MJ, MilicEmily J. A simple method for assessing the validity of the esophageal balloon technique. Am Rev Respir Dis 1982; 126: 788-791.

14. Diehl JL, Atrous S, Touchard D, Lemaire F, Brochard L. Changes in the work of breathing induced by tracheotomy in ventilator dependent patients. $\mathrm{Am}$ J Respir Crit Care Med 1999; 159: 383-388.

15. Sasson CS, Light RW, Ladia R. Pressure time product during continuous positive airway pressure, pressure support ventilation and T-Piece during weaning from mechanical ventilation. Am Rev Respir Dis 1991; 143: 469-475.

16. Lessard MR, Lofaso F, Brochard L. Expiratory muscle activity increases intrinsic positive end-expiratory pressure independently of dynamic hyperinflation in mechanically ventilated patients. Am J Respir Crit Care Med 1995; 151: 562-569.

17. Alberti A, Gallo F, Fongaro A, Valenti S, Rossi A. $P 0.1$ is a useful parameter in setting the level of pressure support ventilation. Intensive Care Med 1995; 21: 547-553.

18. Borg G. Perceived exertion as an indicator of somatic stress. Scand J Rehabil Med 1970; 2: 92-98.

19. Ranieri VM, Grasso S, Mascia L, et al. Effects of proportional assist ventilation on inspiratory muscle effort in patients with chronic obstructive pulmonary disease and acute respiratory failure. Anesthesiology 1997; 86: 79-91.

20. Muza SR, Silverman MT, Gilmore GC. Comparison of scales used to quantitate the sense of effort to breathe in patients with chronic obstructive pulmonary disease. Am Rev Respir Dis 1990; 141: 909-913.

21. Bradley TD, Chartrand DA, Fitting JW, Killian $\mathrm{KJ}$, Grassino A. The relation of inspiratory effort 
sensation to fatiguing patterns of the diaphragm. $\mathrm{Am}$ Rev Respir Dis 1986; 134: 1119-1124.

22. Janson-Bjerklie S, Cornieri V, Hudes M. The sensation of pulmonary dyspnea. Nurs Res 1986; 35: 154-159.

23. Kirton OC, Banner MJ, Axelrad A, Drugas G. Detection of unsuspected imposed work of breathing: ease report. Crit Care Med 1993; 21: 790-795.

24. Younes M. Interactions between patients and ventilators. In: Rousso C, ed. The Thorax. New York, Marcel Dekker, 1995; pp. 2367-2420.

25. Aitken RC. Measurements of feelings using visual analogue scales. Proc Royal Soc Med 1969; 62: 989-993.

26. Manning HL, Molinari EJ, Leiter J. Effect of inspiratory flow rate on respiratory sensation and pattern of breathing. Am J Respir Crit Care Med 1995; 151: 751-757.

27. Grassino A, Bellemare F, Laporta D. Diaphragm fatigue and strategy of breathing in COPD. Chest 1984; 85: 51-54.

28. Knebel AR, Jaoson-Bjerklie SL, Wallen JD, Wilson
AG, Marini JJ. Comparison of breathing comfort during weaning with two ventilatory modes. Am J Respir Crit Care Med 1994; 149: 14-18.

29. Killian KJ, Gandevia SC, Summers E, Campbell EJ. Effect of increased lung volume on perception of breathlessness, effort, and tension. $J$ Appl Physiol 1984; 57: 686-691.

30. Bott J, Carroll MP, Conway JH, et al. Randomised controlled trial of nasal ventilation in acute ventilatory failure due to chronic obstructive airways disease. Lancet 1993; 341: 1555-1557.

31. Brochard L, Harf F, Lorino M, Lemaire F. Inspiratory pressure support prevents diaphragmatic fatigue during weaning from mechanical ventilation. Am Rev Respir Dis 1989; 139: 513-521.

32. Jubran A, Van de Graaff WB, Tobin MJ. Variability of patient-ventilator interaction with pressure support ventilation in patients with chronic obstructive pulmonary disease. Am J Respir Crit Care Med 1995; 152: 129-136. 